\title{
The Clinical Impact of the Age-adjusted Charlson Comorbidity Index on Esophageal Cancer Patients Who Receive Curative Treatment
}

\author{
TORU AOYAMA ${ }^{1 *}$, YOSUKE ATSUMI ${ }^{*}$, SHINNOSUKE KAWAHARA ${ }^{1}$, HIROSHI TAMAGAWA $^{1}$, \\ AYAKO TAMAGAWA ${ }^{1}$, YUKIHIRO OZAWA ${ }^{2}$, YUKIO MAEZAWA ${ }^{1}$, KAZUKI KANO $^{1}$, MASAAKI MURAKAWA ${ }^{1}$, \\ KEISUKE KAZAMA ${ }^{1}$, KENKI SEGAMI ${ }^{1}$, KENTARO HARA ${ }^{1}$, MASAKATSU NUMATA ${ }^{1}$, \\ TAKASHI OSHIMA $^{1}$, NORIO YUKAWA ${ }^{1}$, MUNETAKA MASUDA $^{1}$ and YASUSHI RINO ${ }^{1}$ \\ ${ }^{1}$ Department of Surgery, Yokohama City University, Yokohama, Japan; \\ ${ }^{2}$ Department of Surgery, Miura City Hospital, Miura, Japan
}

\begin{abstract}
Background/Aim: We investigated the impact of the age-adjusted Charlson comorbidity index (ACCI) on esophageal cancer survival and recurrence after curative treatment. Patients and Methods: This study included 122 patients who underwent curative surgery followed by adjuvant chemotherapy for esophageal cancer between 2005 and 2017. The risk factors for the overall survival (OS) and recurrencefree survival (RFS) were identified. Results: An ACCI of 5 was regarded as the optimal critical point of classification considering the survival rates. The OS rates at 3 and 5 years after surgery were $64.2 \%$ and $54.4 \%$ in the low-ACCI group, respectively, and $42.3 \%$ and $29.2 \%$ in high-ACCI group, respectively $(p=0.035)$. The RFS rates at 3 and 5 years after surgery were $50.2 \%$ and $43.6 \%$ in the low-ACCI group, respectively, and $28.5 \%$ and $21.3 \%$ in high-ACCI group, respectively $(p=0.021)$. A multivariate analysis demonstrated that ACCI was a significant independent risk factor for both the OS and RFS. Conclusion: ACCI is a risk factor for survival in patients who undergo curative treatment for esophageal cancer. An effective plan for the perioperative care and surgical strategy should be developed according to ACCI.
\end{abstract}

Esophageal cancer is the seventh-most common cancer and the sixth leading cause of cancer-related mortality. An

This article is freely accessible online.

*These Authors contributed equally to this study.

Correspondence to: Toru Aoyama, Yokohama City University, Yokohama, Japan; 3-9 Fukuura, Kanazawa-ku, Nakao, Yokohama 2360004, Japan. Tel: +81 457872800, e-mail: t-aoyama@lilac.plala.or.jp

Key Words: Age-adjusted Charlson Comorbidity Index, esophageal cancer, curative treatment. estimated 470,000 new esophageal cancer cases and 400,000 deaths occurred worldwide every year $(1,2)$. Esophagectomy with perioperative chemotherapy is the standard treatment for locally advanced esophageal cancer (3-5). However, almost half of patients suffer recurrence, even after curative surgery.

Recently, the number of the elderly esophageal cancer patients has been rapidly growing. Elderly esophageal cancer patients generally have co-morbidities and age-related physiological problems (6-8). Previous reports have shown that the postoperative surgical complication rates after esophagectomy are $30 \%$ to $70 \%$, and the mortality rate is $1 \%-5 \%$ (9-12). Given this situation, perioperative management might be difficult in elderly esophageal cancer patients. To improve the outcomes of locally advanced esophageal cancer patients, it is necessary to establish an optimal treatment strategy.

The Charlson comorbidity index (CCI) was first proposed by Charlson et al. in 1987 (13). The CCI was initially developed to account for the influence of patients' adverse medical conditions and is useful for prognostic prediction by weighing and scoring each comorbidity disease. This scoring index is widely used to evaluate the impact of comorbidities on a variety of conditions. In addition, the age-adjusted CCI (ACCI) includes the age of the patient as a correction variable in the final score, and several studies have shown ACCI to be a useful tool for predicting both the short- and long-term outcomes of various cancers (14-16). Given the above, ACCI might be a useful tool for establishing the optimal treatment strategy of esophageal cancer patients.

In the present study, we evaluated the clinical impact of ACCI on both the overall survival (OS) and recurrence-free survival (RFS) in esophageal cancer patients who underwent curative treatment. 
Table I. Comparison of survival rates stratified by patient characteristics.

\begin{tabular}{|c|c|c|c|c|c|}
\hline Characteristics & $\begin{array}{c}\text { No. of } \\
\text { patients (\%) }\end{array}$ & $\begin{array}{c}1 \text {-year } \\
\text { survival rate }(\%)\end{array}$ & $\begin{array}{c}\text { 3-year } \\
\text { survival rate (\%) }\end{array}$ & $\begin{array}{c}\text { 5-year } \\
\text { survival rate (\%) }\end{array}$ & $p$-Value \\
\hline Age (years) & & & & & 0.0024 \\
\hline$<75$ & $98(80.3)$ & 84.0 & 69.5 & 54.5 & \\
\hline$\geq 75$ & $24(19.7)$ & 62.5 & 39.5 & 14.8 & \\
\hline Gender & & & & & 0.3772 \\
\hline Male & $16(13.1)$ & 85.7 & 77.9 & 64.9 & \\
\hline Female & $106(86.9)$ & 78.6 & 54.2 & 46.4 & \\
\hline Site of tumor & & & & & 0.9167 \\
\hline Upper & $86(70.5)$ & 71.4 & 58.8 & 44.1 & \\
\hline Middle or lower & $36(29.5)$ & 78.0 & 49.9 & 45.7 & \\
\hline Age adjusted Charlson comorbidity index & & & & & 0.0352 \\
\hline $3-4$ & $74(60.7)$ & 84.9 & 64.2 & 54.4 & \\
\hline $5-6$ & $27(22.1)$ & 68.5 & 41.2 & 41.2 & \\
\hline $7-8$ & $21(17.2)$ & 75.0 & 43.1 & 17.3 & \\
\hline UICC T status & & & & & 0.0001 \\
\hline $\mathrm{T} 1$ & $43(35.2)$ & 93.0 & 75.1 & 71.3 & \\
\hline $\mathrm{T} 2$ to $\mathrm{T} 3$ & $79(64.8)$ & 68.1 & 39.6 & 30.8 & \\
\hline Lymph vascular invasion & & & & & 0.0427 \\
\hline Negative & $38(31.1)$ & 89.0 & 69.9 & 64.1 & \\
\hline Positive & $84(68.9)$ & 75.4 & 49.7 & 41.1 & \\
\hline Pathological lymph node status & & & & & 0.0219 \\
\hline Negative & $62(50.8)$ & 85.1 & 66.4 & 60.4 & \\
\hline Positive & $60(49.2)$ & 74.2 & 45.4 & 35.9 & \\
\hline Neoadjuvant therapy & & & & & 0.7701 \\
\hline Yes & $71(58.2)$ & 84.5 & 58.8 & 49.5 & \\
\hline No & $51(41.8)$ & 76.1 & 61.0 & 46.6 & \\
\hline
\end{tabular}

UICC: Union for International Cancer Control.

\section{Patients and Methods}

Patients. Patients who underwent esophagectomy for esophageal cancer at Yokohama City University between 2005 and 2017 were selected from the medical records. The patients had histologically proven primary esophageal squamous cell or adenocarcinoma, clinical stage IB to III, as evaluated using the 7th edition of the Union for International Cancer Control (UICC), and they underwent complete resection of the esophageal cancer with lymph node dissection.

Surgical procedure. Our standard procedures consisted of open subtotal esophagectomy via right thoracotomy. Reconstruction was performed with a gastric tube through the posterior mediastinal or retrosternal route. Anastomosis was performed via cervical incision. Three-field dissection was performed for upper thoracic tumors, while two-field lymph node dissection was indicated when tumors were located at the middle thoracic to lower thoracic esophagus.

Calculation of ACCI. In the present study, the ACCI was evaluated as defined by Charlson. A score of 1 was assigned for congestive heart failure, myocardial infarction, cerebrovascular disease, dementia, peripheral vascular disease, connective tissue disease, chronic obstructive pulmonary disease (COPD), mild liver disease, ulcer disease, or diabetes mellitus without end-organ damage, a score of 2 for moderate-to-severe chronic kidney disease, hemiplegia, solid tumor, diabetes with end-organ damage, lymphoma, or leukemia, a score of 3 for moderate-to-severe liver disease, and a score of 6 for acquired immunodeficiency syndrome and metastatic solid tumors ( 1 point added for each decade over 40 years of age).

Evaluations and statistical analyses. The significance of correlations between ACCI and clinic pathological parameters was determined using Fisher's exact test or the $\chi^{2}$ test. The OS and RFS were evaluated by univariate and multivariate analyses. The OS and RFS curves were calculated using the Kaplan-Meier method and compared by the log-rank test. A Cox proportional hazards model was used to perform the univariate and multivariate survival analyses. $p$-Values of $<0.05$ were considered to indicate statistical significance. The SPSS software program (v11.0 J Win; SPSS, Chicago, IL, USA) was used for all of the statistical analyses. This study was approved by the Institutional Review Board of Yokohama City University.

\section{Results}

Patients. We evaluated 122 patients in the present study. The median age was 68 years old (range $=40-82$ years); 106 patients were male, and 16 were female. The median follow-up period was 72.5 months (range=13.9-125.2 months). The median length of the operation was $573 \mathrm{~min}$ (range=236-911 $\mathrm{min}$ ). The median blood loss was $541 \mathrm{ml}$ (range=70-3000 ml). The median number of harvest lymph nodes was 37 (range=3-118). 
Table II. Uni- and multi-variate Cox proportional hazards analysis of clinicopathological factors for overall survival.

\begin{tabular}{|c|c|c|c|c|c|c|c|}
\hline \multirow[t]{2}{*}{ Factors } & \multirow[t]{2}{*}{ No } & \multicolumn{3}{|c|}{ Univariate analysis } & \multicolumn{3}{|c|}{ Multivariate analysis } \\
\hline & & OR & $95 \% \mathrm{CI}$ & $p$-Value & OR & $95 \% \mathrm{CI}$ & $p$-Value \\
\hline Age (years) & & & & 0.121 & & & 0.002 \\
\hline$<75$ & 98 & 1.000 & & & 1.000 & & \\
\hline$\geq 75$ & 24 & 1.507 & $0.898-2.529$ & & 2.598 & $1.424-4.740$ & \\
\hline Gender & & & & 0.139 & & & \\
\hline Female & 16 & 1.000 & & & & & \\
\hline Male & 106 & 2.153 & $0.780-5.949$ & & & & \\
\hline $\begin{array}{l}\text { Age adjusted Charlson } \\
\text { comorbidity index }\end{array}$ & & & & 0.011 & & & 0.017 \\
\hline$\leq 4$ & 74 & 1.000 & & & 1.000 & & \\
\hline$\geq 5$ & 48 & 1.982 & $1.168-3.364$ & & 1.932 & $1.126-3.313$ & \\
\hline Site of tumor & & & & 0.392 & & & \\
\hline Middle or lower & 86 & 1.000 & & & & & \\
\hline Upper & 36 & 1.331 & $0.691-2.564$ & & & & \\
\hline UICC $\mathrm{T}$ status & & & & 0.006 & & & 0.001 \\
\hline $\mathrm{T} 1$ & 43 & 1.000 & & & 1.000 & & \\
\hline $\mathrm{T} 2$ or $\mathrm{T} 3$ & 79 & 2.387 & $1.286-4.430$ & & 2.158 & $1.589-2.931$ & \\
\hline Pathological lymph node status & & & & 0.019 & & & \\
\hline Negative & 62 & 1.000 & & & & & \\
\hline Positive & 60 & 1.885 & $1.111-3.196$ & & & & \\
\hline Lymph vascular invasion & & & & 0.020 & & & \\
\hline Negative & 38 & 1.000 & & & & & \\
\hline Positive & 84 & 2.182 & $1.131-4.210$ & & & & \\
\hline Neoadjuvant therapy & & & & 0.881 & & & \\
\hline Yes & 71 & 1.000 & & & & & \\
\hline No & 51 & 1.041 & $0.612-1.771$ & & & & \\
\hline
\end{tabular}

UICC: Union for International Cancer Control.

Survival analyses and patient's characteristics. The OS stratified by each clinical factor was compared using the logrank test, and a significant difference was observed in age ( $<75 v s . \geq 75$ years old), UICC T factor (T1 vs. T2 to T3), lymphovascular invasion (positive vs. negative), and ACCI (3-4 vs. 5-6 vs. 7-8) (Table I). An ACCI of 4 was regarded as the optimal critical point for classification, considering the 1- to 5-year survival rate.

Each clinicopathological factor was categorized as shown in Table II and was analyzed for its prognostic significance. The univariate analyses for the OS showed that ACCI was a significant prognostic factor. The ACCI was therefore selected for the final multivariate analysis model. The OS rates at 3 and 5 years after surgery were $64.2 \%$ and $54.4 \%$ in the low-ACCI group, respectively, and $42.3 \%$ and $29.2 \%$ in the high-ACCI group, respectively, which amounted to a statistically significant difference $(p=0.035)$. The OS curves are shown in Figure 1.

The univariate analyses for RFS showed that ACCI was a significant prognostic factor. ACCI was therefore selected for the final multivariate analysis model (Table III). The RFS rates at 3 and 5 years after surgery were $50.2 \%$ and $43.6 \%$ in the low-ACCI group, respectively, and $28.5 \%$ and $21.3 \%$ in the high-ACCI group, respectively, which amounted to a marginally statistically significant difference $(p=0.021)$. The RFS curves are shown in Figure 2.

When comparing the patients' demographic and clinical characteristics between the low- and high-ACCI groups, the incidence of postoperative anastomosis leakage (AL) was significantly different between the two groups. The incidence of AL was $27 \%$ in the low-ACCI group and $54 \%$ in the highACCI group. In addition, when comparing the sites of first relapse, the incidence of lung metastasis was significantly higher in the high-ACCI group than in the low-ACCI group (Table IV).

\section{Discussion}

The present study evaluated the clinical influence of ACCI on the survival of esophageal cancer patients who received curative surgery. The major finding was that ACCI was a significant risk factor for both the OS and RFS in esophageal cancer patients, indicating that age-related physiological problems and preoperative co-morbidities affected cancer treatment outcomes. To improve the survival of esophageal cancer patients who 


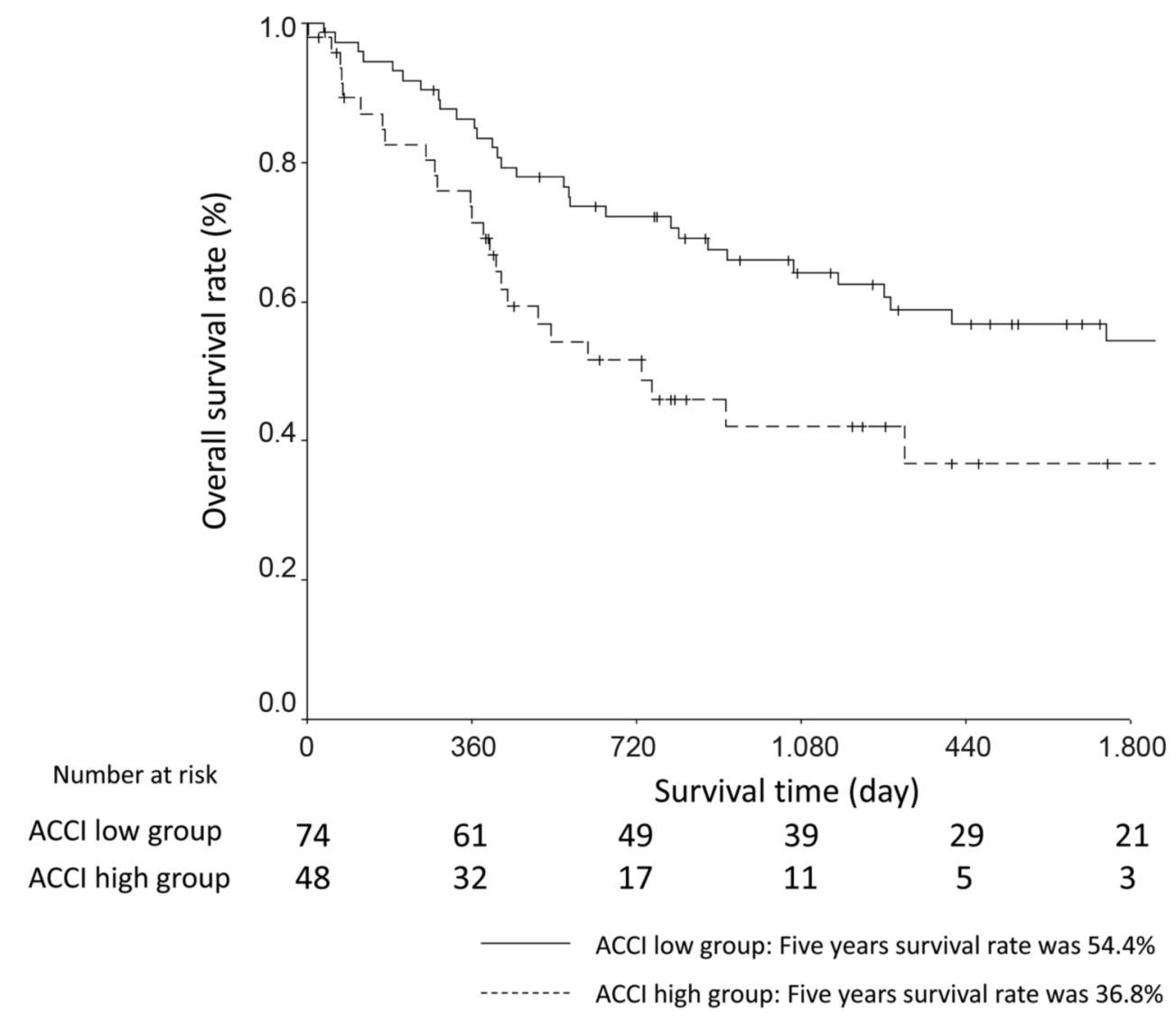

Figure 1. A comparison of the overall survival in patients with an $A C C I \geq 5$ and those with an ACCI $\leq 4$.

receive curative surgery, assessing ACCI might be useful for establishing an ideal treatment strategy for esophageal cancer.

First, we want to discuss the clinical influence of ACCI for esophageal cancer patients. In the present study, we showed that the OS rates at 5 years after surgery were $54.4 \%$ in the low-ACCI group and $29.2 \%$ in the high-ACCI group [hazard ratio $(\mathrm{HR})=1.932,95 \%$ confidence interval $(\mathrm{CI})=1.126-3.313, p=0.035]$. A few studies have described the relationship between ACCI and survival for gastrointestinal cancer patients. Maezawa et al. investigated the survival impacts of ACCI in 2254 patients who received radical gastrectomy for gastric cancer (17). They divided the patients into two groups: low-ACCI group $(n=1656)$ and high-ACCI group $(n=598)$. They found that the 5-year OS rate was $85.4 \%$ in the low-ACCI group and $74.1 \%$ in the high-ACCI group, showing a significant difference between the groups $(\mathrm{HR}=1.80,95 \% \mathrm{CI}=1.46-2.23, p<0.001)$. In addition, the 5-year RFS was $83.1 \%$ in the low-ACCI group and $73.4 \%$ in the high-ACCI group $(\mathrm{HR}=1.44,95 \% \mathrm{CI}=1.15-$ $1.80, p=0.001$ ). Lin et al. evaluated the clinical impact of ACCE in 1476 gastric cancer patients who received curative surgery (18). They reported that there were significant differences in the OS between the low- and high-ACCI groups. The 1-, 3-, and 5-year OS rates were 82.7\%, 62.4\%, and $56.4 \%$ in the low-ACCI group, respectively, and $81.6 \%$, $57.2 \%$, and $47.5 \%$ in the high-ACCI group, respectively. In addition, Lin et al. also evaluated the clinical impact of ACCI in 2257 patients who received curative gastrectomy for gastric cancer (19). They found that ACCI was an independent risk factor in gastric cancer. They reported that the HR for the OS increased with increasing ACCI score [ACCI score 0-1; reference; ACCI score 2: $\mathrm{HR}=1.324$ (95\% CI=1.612-2.382),$\quad p=0.003 ; \quad$ ACCI score 3-10: $\mathrm{HR}=1.894(95 \% \mathrm{CI}=1.612-2.382), p<0.001]$. These previous findings indicate that ACCI has some clinical impact on the survival of gastrointestinal cancer, including esophageal cancer.

One possible explanation for the reason why did ACCI affect esophageal cancer patients' survival could be that it might be associated with postoperative surgical complications. In the present study, the incidence of AL was $27 \%$ in the low-ACCI group and 54\% in the high-ACCI group. Similar results have been observed in other studies. In the colorectal cancer field, Tian et al. evaluated the 
Table III. Uni- and multi-variate Cox proportional hazards analysis of clinicopathological factors for recurrence free survival.

\begin{tabular}{|c|c|c|c|c|c|c|c|}
\hline \multirow[t]{2}{*}{ Factors } & \multirow[t]{2}{*}{ No } & \multicolumn{3}{|c|}{ Univariate analysis } & \multicolumn{3}{|c|}{ Multivariate analysis } \\
\hline & & OR & $95 \% \mathrm{CI}$ & $p$-Value & OR & $95 \% \mathrm{CI}$ & $p$-Value \\
\hline Age (years) & & & & 0.742 & & & \\
\hline$\leq 75$ & 98 & 1.000 & & & & & \\
\hline$\geq 75$ & 24 & 1.091 & $0.651-1.828$ & & & & \\
\hline Gender & & & & 0.282 & & & \\
\hline Female & 16 & 1.000 & & & & & \\
\hline Male & 106 & 1.590 & $0.683-3.702$ & & & & \\
\hline $\begin{array}{l}\text { Age adjusted Charlson } \\
\text { comorbidity index }\end{array}$ & & & & 0.010 & & & 0.001 \\
\hline$\leq 4$ & 74 & 1.000 & & & 1.000 & & \\
\hline$\geq 5$ & 48 & 1.863 & $1.158-2.998$ & & 2.241 & $1.375-3.651$ & \\
\hline Site of tumor & & & & 0.853 & & & \\
\hline Middle or lower & 86 & 1.000 & & & & & \\
\hline Upper & 36 & 1.032 & $0.737-1.447$ & & & & \\
\hline UICC T status & & & & $<0.001$ & & & 0.001 \\
\hline $\mathrm{T} 1$ & 43 & 1.000 & & & 1.000 & & \\
\hline $\mathrm{T} 2$ or $\mathrm{T} 3$ & 79 & 4.623 & $2.265-9.434$ & & 1.980 & $1.527-2.567$ & \\
\hline Pathological lymph node status & & & & $<0.001$ & & & \\
\hline Negative & 62 & 1.000 & & & & & \\
\hline Positive & 60 & 2.664 & $1.546-4.590$ & & & & \\
\hline Lymph vascular invasion & & & & 0.005 & & & \\
\hline Negative & 38 & 1.000 & & & & & \\
\hline Positive & 84 & 2.588 & $1.341-4.995$ & & & & \\
\hline Neoadjuvant therapy & & & & 0.089 & & & \\
\hline Yes & 71 & 1.000 & & & & & \\
\hline No & 51 & 1.620 & $0.928-2.827$ & & & & \\
\hline
\end{tabular}

UICC: Union for International Cancer Control.

Table IV. Patterns of recurrence between the patients with age adjusted Charlson comorbidity index $<4$ and those with age adjusted Charlson comorbidity index $\geq 5$.

\begin{tabular}{|c|c|c|c|c|c|c|c|}
\hline \multirow[b]{3}{*}{ Recurrence site } & & & \multicolumn{4}{|c|}{ Age adjusted Charlson comorbidity index } & \multirow[t]{3}{*}{$p$-Value } \\
\hline & \multicolumn{2}{|c|}{ All cases } & \multicolumn{2}{|c|}{$<4(\mathrm{n}=74)$} & \multicolumn{2}{|c|}{$\geq 5(n=48)$} & \\
\hline & Number & $\%$ & Number & $\%$ & Number & $\%$ & \\
\hline \multicolumn{8}{|l|}{ Lymph node } \\
\hline Regional & 23 & 18.9 & 13 & 17.6 & 10 & 20.8 & 0.6523 \\
\hline Distant & 7 & 5.7 & 3 & 4.1 & 4 & 8.3 & 0.3208 \\
\hline Local site & 12 & 9.8 & 8 & 10.8 & 4 & 8.3 & 0.6535 \\
\hline \multicolumn{8}{|l|}{ Distant site } \\
\hline Lung & 12 & 9.8 & 3 & 4.1 & 9 & 18.8 & 0.0078 \\
\hline Liver & 11 & 9.0 & 7 & 9.5 & 4 & 8.3 & 0.8320 \\
\hline Bone & 5 & 4.1 & 3 & 4.1 & 2 & 4.2 & 0.9755 \\
\hline Others & 9 & 8.0 & 4 & 5.4 & 5 & 10.4 & 0.3009 \\
\hline Disseminated & 3 & 2.5 & 1 & 1.3 & 2 & 4.2 & 0.3267 \\
\hline
\end{tabular}

association of the ACCI score and the incidence of postoperative ileus in 11,397 colorectal cancer patients (20). They found that the incidence of postoperative ileus after rectal cancer surgery was $1.2 \%$ in the ACCI score 0-1 group,
$1.6 \%$ in the ACCI score $2-3$ group, $2.5 \%$ in the ACCI $4-5$ group, and $2.7 \%$ in the ACCI $\geq 6$ group. Furthermore, the incidence of postoperative ileus after colon cancer surgery was $7.8 \%$ in the ACCI score $0-1$ group, $7.0 \%$ in the ACCI 


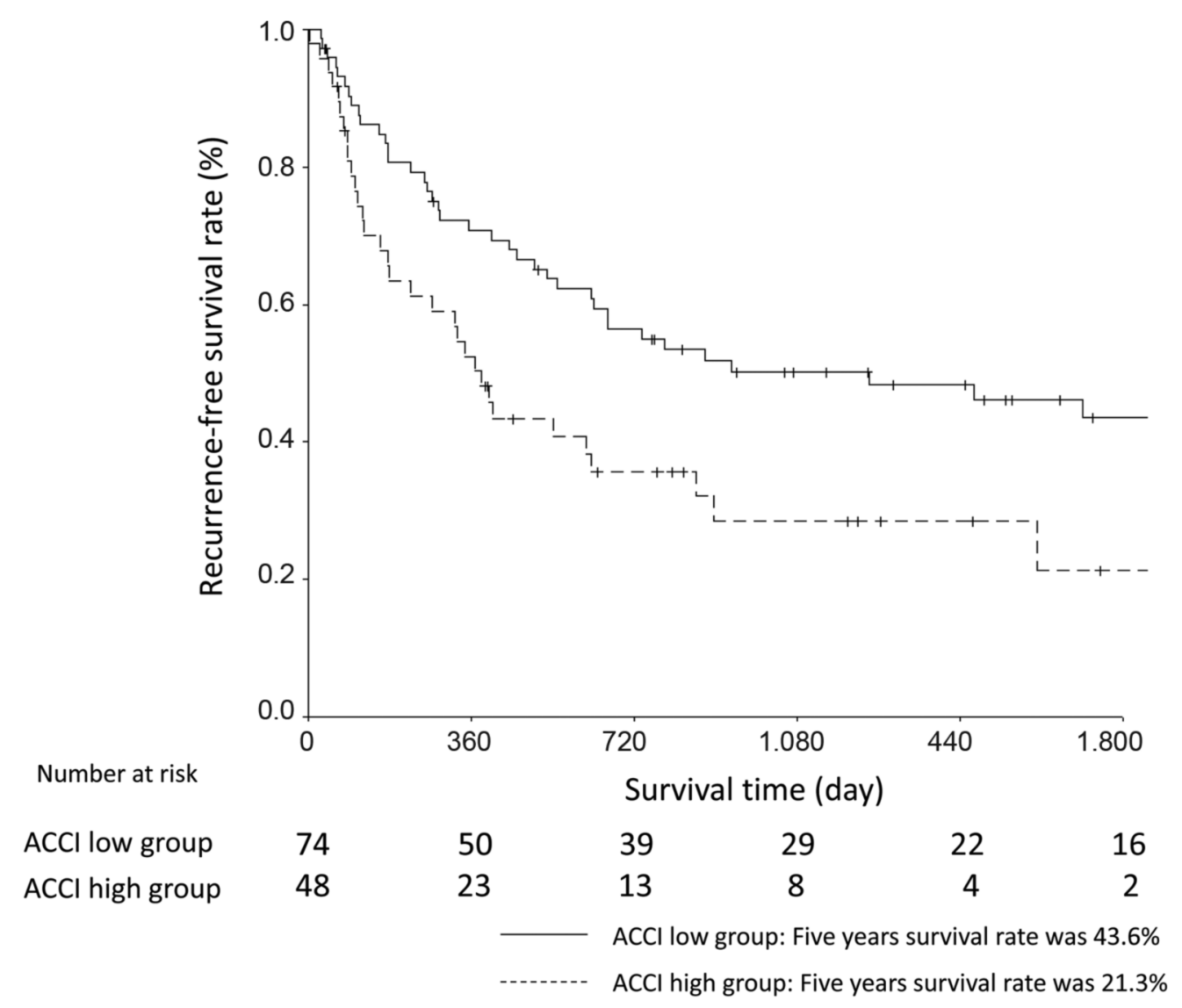

Figure 2. A comparison of the recurrence-free survival in patients with an ACCI $\geq 5$ and those with an ACCI $\leq 4$.

score 2-3 group, $7.6 \%$ in the ACCI $4-5$ group, and $11.8 \%$ in the ACCI $\geq 6$ group. We have previously found that postoperative anastomotic leakage was a significant independent risk factor for esophageal cancer patients who received curative treatment. In a previous study, the 5-year survival rate was $40.2 \%$ in patients with $\mathrm{AL}$ and $53.2 \%$ in the patients without AL (21). Therefore, postoperative surgical complications might occur in groups with high ACCI, resulting in a poor prognosis. Future studies should clarify the mechanism underlying the relationship between ACCI and prognosis.

We also want to discuss the cut-off value of the ACCI for cancer survival. In the present study, we set the cut-off value at 4 according to the 1 - to 5-year survival rate. To utilize ACCI for esophageal cancer treatment, it is necessary to establish the optimal cut-off value. Several studies have previously explored the appropriate cut-off value of ACCI in several cancers. In the gastrointestinal region, Lin et al. set 3 as the cut-off value in 1476 gastric cancer patients, and Maezawa et al. set 6 as the cut-off value in 2254 gastric cancer patients $(17,18)$. In the hepato-biliary pancreatic cancer region, Qu et al. set 4 as the cut-off value in 268 intrahepatic cholangiocarcinoma patients, and Takahara et al. set 5 as the cut-off value in biliary tract cancer $(22,23)$. Although it is difficult to establish a definitive cut-off value due to differences among cancer types, patients' background characteristics, and the number of patients, a cut-off value of 3-5 might be useful for ACCI. Future studies should focus on this issue to clarify the optimum cut-off value for the ACCI.

Several limitations associated with the present study should be mentioned. First, the present study was retrospective and conducted at a single institution. Therefore, there might have been some selection bias. Second, there might have been some time bias in our study. The patient records in the present study were collected between 2005 and 2017. During this period, the perioperative management and perioperative adjuvant treatment changed, and these changes might have affected the present study results. As such, the present study results should be validated in another cohort.

In conclusion, ACCI was a significant risk factor for both the OS and RFS in esophageal cancer patients. Age-related 
physiological problems and preoperative co-morbidities affected cancer treatment outcomes. The assessment of ACCI might be useful for establishing the treatment strategy for esophageal cancer.

\section{Conflicts of Interest}

The Authors declare no conflicts of interest in association with the present study.

\section{Authors' Contributions}

Toru Aoyama and Yosuke Atsumi made substantial contributions to conception and design. Norio Yukawa, Kenki Segami, Toru Aoyama, Hiroshi Tamagawa, Ayako Tamagawa, Yosuke Atsumi, Shinnosuke Kawahara, Yukio Maezawa, Kazuki Kano, Kentaro Hara, Masaaki Murakawa, Keisuke Kazama, Masakatsu Numata, Takashi Oshima, Munetaka Masuda, and Yasushi Rino made substantial contributions to acquisition of data, or analysis and interpretation of data. Norio Yukawa, Toru Aoyama, Hiroshi Tamagawa, Ayako Tamagawa, Yosuke Atsumi, and Shinnosuke Kawahara have been involved in drafting the manuscript or revising it critically for important intellectual content. Norio Yukawa, Toru Aoyama, Hiroshi Tamagawa, Ayako Tamagawa, Yosuke Atsumi, and Shinnosuke Kawahara have given final approval of the version to be published. Each Author participated sufficiently in the work to take public responsibility for appropriate portions of the content, and agreed to be accountable for all aspects of the work in ensuring that questions related to the accuracy or integrity of any part of the work are appropriately investigated and resolved. All Authors read and approved the final manuscript.

\section{Acknowledgements}

This work was supported, in part, by the nongovernmental organization Yokohama Surgical Research Group, Dr. Masumi Kamachi (Tokyo Shinagawa Hospital), Dr. Ryuji Tominaga (Fukuoka Wajiro Hospital), Dr. Nobuko Yoshiki (Yoshiki Dermatology Clinic Ginza). The Authors express their sincere gratitude to Ms. Akiko Yoshida, Ms. Yuka Maruyama, Ms. Minako Igarashi and Ms. Mariko Yamauchi for their excellent data management in this study.

\section{References}

1 Bray F, Ferlay J, Soerjomataram I, Siegel RL, Torre LA and Jemal A: Global cancer statistics 2018: GLOBOCAN estimates of incidence and mortality worldwide for 36 cancers in 185 countries. CA Cancer J Clin 68: 394-424, 2018. PMID: 30207593. DOI: 10.3322/caac.21492

2 Torre LA, Bray F, Siegel RL, Ferlay J, Lortet-Tieulent J and Jemal A: Global cancer statistics, 2012. CA Cancer J Clin 65: 87-108, 2015. DOI: 10.3322/caac.21262. PMID: 25651787.

3 NCCN: NCCN Clinical Practice Guidelines in Oncology. Available at: https://www.nccn.org/professionals/physician_gls/ default.aspx [Last accessed 1 May 2020]

4 Muro K, Lordick F, Tsushima T, Pentheroudakis G, Baba E, Lu Z, Cho BC, Nor IM, Ng M, Chen LT, Kato K, Li J, Ryu MH,
Zamaniah WIW, Yong WP, Yeh KH, Nakajima TE, Shitara K, Kawakami H, Narita Y, Yoshino T, Van Cutsem E, Martinelli E, Smyth EC, Arnold D, Minami H, Tabernero J and Douillard JY: Pan-Asian adapted ESMO Clinical Practice Guidelines for the management of patients with metastatic oesophageal cancer: a JSMO-ESMO initiative endorsed by CSCO, KSMO, MOS, SSO and TOS. Ann Oncol 30: 34-43, 2019. PMID: 30475943. DOI: 10.1093/annonc/mdy498

5 Lordick F, Mariette C, Haustermans K, Obermannová R and Arnold D; ESMO guidelines Committee. Oesophageal cancer: ESMO Clinical Practice Guidelines for diagnosis, treatment and follow-up. Ann Oncol 27: v50-v57, 2016. PMID: 27664261.

6 Han Y, Liu S, Guo W, Zhang Y and Li H: Clinical outcomes of oesophagectomy in elderly versus relatively younger patients: a meta-analysis. Interact Cardiovasc Thorac Surg 29: 897-905, 2019. PMID: 31765482 . DOI: $10.1093 /$ icvts/ivz208

7 Rahamim JS, Murphy GJ, Awan Y and Junemann-Ramirez M: The effect of age on the outcome of surgical treatment for carcinoma of the esophagus and gastric cardia. Eur J Cardiothorac Surg 23: 805-810, 2003. PMID: 12754037. DOI: 10.1016/s1010-7940(03)00034-4.

8 Aoyama T, Hara K, Kazama K, Atsumi Y, Tamagawa H, Tamagawa A, Machida D, Komori K, Maezawa Y, Kano K, Hashimoto I, Oshima T, Murakawa M, Numata M, Yukawa N, Masuda M and Rino Y: The short- and long-term outcomes of esophagectomy for esophageal cancer in patients older than 75 years. Anticancer Res 40: 1087-1093, 2020. PMID: 32014958. DOI: 10.21873 /anticanres.14047

9 Aoyama T, Kazama K, Atsumi Y, Tamagawa H, Tamagawa A, Komori K, Machida D, Maezawa Y, Kano K, Hara K, Murakawa M, Numata M, Oshima T, Yukawa N, Masuda M and Rino Y: Clinical influence of anastomotic leakage on esophageal cancer survival and recurrence. Anticancer Res 40(1): 443-449, 2020. PMID: 31892599. DOI: 10.21873/anticanres.13972

10 Rutegård $\mathrm{M}$, Lagergren $\mathrm{P}$, Rouvelas $\mathrm{I}$ and Lagergren $\mathrm{J}$ : Intrathoracic anastomosis leakage and mortality after esophageal cancer resection: a population-based study. Ann Surg Oncol 19: 99-103, 2012. PMID: 21769467. DOI: 10.1245/s10434-0111926-6

11 Aurello P, Berardi G, Moschetta G, Cinquepalmi M, Antolino L, Nigri G, D'Angelo F, Valabrega $S$ and Ramacciato G: Recurrence following anastomotic leakage after surgery for carcinoma of the distal esophagus and gastroesophageal junction: A systematic review. Anticancer Res 39(4): 1651-1660, 2019. PMID: 30952703. DOI: 10.21873/anticanres.13270.

12 Tamagawa A, Aoyama T, Tamagawa H, Ju M, Komori K, Maezawa Y, Kano K, Kazama K, Murakawa M, Atsumi Y, Sawazaki S, Hara K, Numata M, Sato T, Yukawa N, Masuda M and Rino Y: Influence of postoperative pneumonia on esophageal cancer survival and recurrence. Anticancer Res 39: 2671-2678, 2019. PMID: 31092467. DOI: 10.21873/anticanres.13392

13 Charlson ME, Pompei P, Ales KL and MacKenzie CR: A new method of classifying prognostic comorbidity in longitudinal studies: development and validation. J Chronic Dis 40: 373-383, 1987. PMID: 3558716. DOI: 10.1016/0021-9681(87)90171-8

14 Charlson M, Szatrowski TP, Peterson J and Gold J: Validation of a combined comorbidity index. J Clin Epidemiol 47: 1245-1251, 1994. PMID: 7722560. DOI: 10.1016/0895-4356(94)90129-5

15 Wu CC, Hsu TW, Chang CM, Yu CH and Lee CC: Age-adjusted Charlson comorbidity index scores as predictor of survival in 
colorectal cancer patients who underwent surgical resection and chemoradiation. Medicine (Baltimore) 94: e431, 2015. PMID: 25590852. DOI: 10.1097/MD.0000000000000431

16 Tian Y, Jian Z, Xu B and Liu H: Age-adjusted Charlson comorbidity index score as predictor of survival of patients with digestive system cancer who have undergone surgical resection. Oncotarget 8: 79453-79461, 2017. PMID: 29108324. DOI: 10.18632/oncotarget.18401

17 Maezawa Y, Aoyama T, Kano K, Tamagawa H, Numata M, Hara K, Murakawa M, Yamada T, Sato T, Ogata T, Oshima T, Yukawa $\mathrm{N}$, Yoshikawa T, Masuda M and Rino Y: Impact of the Ageadjusted Charlson comorbidity index on the short- and long-term outcomes of patients undergoing curative gastrectomy for gastric cancer. J Cancer 10: 5527-5535, 2019. PMID: 31632496. DOI: $10.7150 /$ jca. 35465

18 Lin JX, Huang YQ, Xie JW, Wang JB, Lu J, Chen QY, Cao LL, Lin M, Tu RH, Huang ZN, Lin JL, Li P, Huang CM and Zheng $\mathrm{CH}$ : Age-adjusted Charlson Comorbidity Index (ACCI) is a significant factor for predicting survival after radical gastrectomy in patients with gastric cancer. BMC Surg 19: 53, 2019. PMID: 31133008. DOI: 10.1186/s12893-019-0513-9.

19 Lin JX, Huang YQ, Xie JW, Wang JB, Lu J, Chen QY, Cao LL, Lin M, Tu R, Huang ZN, Lin JL, Zheng CH, Huang CM and Li P: Association of the age-adjusted Charlson Comorbidity Index and systemic inflammation with survival in gastric cancer patients after radical gastrectomy. Eur J Surg Oncol 45: 24652472, 2019. PMID: 31350072. DOI: 10.1016/j.ejso.2019.07.010

20 Tian Y, Xu B, Yu G, Li Y and Liu H: Age-adjusted Charlson comorbidity index score as predictor of prolonged postoperative ileus in patients with colorectal cancer who underwent surgical resection. Oncotarget 8: 20794-20801, 2017. PMID: 28206969. DOI: $10.18632 /$ oncotarget.15285
21 Aoyama T, Kazama K, Atsumi Y, Tamagawa H, Tamagawa A, Komori K, Machida D, Maezawa Y, Kano K, Hara K, Murakawa M, Numata M, Oshima T, Yukawa N, Masuda M and Rino Y: Clinical influence of anastomotic leakage on esophageal cancer survival and recurrence. Anticancer Res 40: 443-449, 2020. PMID: 31892599. DOI: 10.21873/anticanres.13972

22 Qu WF, Zhou PY, Liu WR, Tian MX, Jin L, Jiang XF, Wang H, Tao CY, Fang Y, Zhou YF, Song SS, Ding ZB, Peng YF, Dai Z, Qiu SJ, Zhou J, Fan J, Tang Z and Shi YH: Age-adjusted Charlson Comorbidity Index predicts survival in intrahepatic cholangiocarcinoma patients after curative resection. Ann Transl Med 8: 487, 2020. PMID: 32395531. DOI: 10.21037/atm. 2020.03 .23

23 Takahara N, Nakai Y, Saito K, Sasaki T, Suzuki Y, Inokuma A, Oyama H, Kanai S, Suzuki T, Sato T, Hakuta R, Ishigaki K, Saito T, Hamada T, Mizuno S, Kogure H, Tada M, Isayama H and Koike K: The impact of age and comorbidity in advanced or recurrent biliary tract cancer receiving palliative chemotherapy. J Gastroenterol Hepatol, 2020. PMID: 32267557. DOI: $10.1111 /$ jgh. 15066
Received June 2, 2020

Revised June 22, 2020

Accepted June 24, 2020 